\title{
BM] Global Health Closing the blood pressure gap: an affordable proposal to save lives worldwide
}

\author{
David J Heller, Sandeep P Kishore
}

To cite: Heller DJ, Kishore SP. Closing the blood pressure gap: an affordable proposal to save lives worldwide. BMJ Glob Health 2017;2:e000429. doi:10.1136/ bmjgh-2017-000429

Handling editor Seye Abimbola

Received 30 May 2017 Revised 1 August 2017 Accepted 24 August 2017

CrossMark

Arnhold Institute for Global Health, Icahn School of Medicine at Mount Sinai, New York City, New York, USA

Correspondence to Dr David J Heller; david.heller@mssm.edu
Thanks to aggressive action over the past 15 years, death and disease from HIV and AIDS has steadily declined, ${ }^{1}$ and with new evidence that treating HIV also prevents transmission, discussions of the 'end of AIDS' grow louder. ${ }^{2}$ Support for HIV/AIDS control programmes such as the Global Fund for AIDS, Tuberculosis, and Malaria and the US President's Emergency Plan for AIDS Relief (PEPFAR) is near-universal among both donor countries and private sector sponsors. Asked about doubling HIV medication access through PEPFAR in 2016, US President Donald Trump remarked that he 'believe[s] so strongly in that...we're going to lead the way, ${ }^{3}$ even as his administration proposes eliminating other global health infrastructure. ${ }^{4}$ Why did the fight to end HIV gain such political and financial commitment worldwide? It defined and addressed a specific, fixable problemand a resource gap to close it.

In 2001, after two decades of inaction had turned AIDS into a worldwide emergency so severe that the United Nations (UN) Security Council declared it a threat to global political stability, ${ }^{5}$ the nascent Joint United Nations Programme on HIV/AIDS mapped out how many persons were missing treatment and the price to cover them. ${ }^{6}$ Later that year, the Commission on Macroeconomics and Health released a report demonstrating this effort would 'not only save millions of lives but also produce enormous economic gains', ${ }^{7}$ which galvanised support that launched the Global Fund for AIDS, Tuberculosis, and Malaria in $2002 .{ }^{8}$ By 2003 , the WHO had a strategy for how to close that treatment gap for 3 million people within 2 years. ${ }^{9}$ US President George W. Bush launched PEPFAR that year, providing initial financing and logistics to close that gap ${ }^{10}$-at a summit that June, other wealthy countries pledged to follow suit. ${ }^{11}$ Identifying a discrete unmet need-for a set number of persons to get life-saving medication for a set price-and proving the economic value of closing that gap
Summary box

Hypertension is the leading risk factor for death worldwide and is now more common in low-income and middle-income countries (LMICs) than high-income ones. However, hypertension control programmes are massively underfunded relative to their contribution to global disease burden, in contrast to efforts to control HIV/AIDS and other infectious diseases.

- New data reveal the size of the burden of hypertension in LMICs, the cost of its treatment and the number of lives saved per patient treated. These data suggest that treatment of all persons in LMICs with uncomplicated hypertension would cost $\$ 7.6$ billion annually and save 4.7 million lives over a decade, at a total cost of roughly $\$ 16000$ per life saved.

- These numbers now compare favourably with the impact and cost-effectiveness estimates that kickstarted global health programmes such as the Global Fund to Fight AIDS, Tuberculosis and Malaria, and rebut prior claims that universal hypertension treatment is not yet cost-effective.

- Advocates and policymakers should use these data to argue for increased funding for hypertension care in developing countries. Even in a political climate marked by antiglobalism, populism and scepticism of international aid and development, investment in hypertension control is sufficiently costeffective-from both humanitarian and strategic perspectives - for bilateral and non-governmental donors to rally behind.

provided hard numbers donors and governments could get behind. With that support, the tide turned. Initial costs were substantialup to $\$ 3500$ (USD) per year for antiretroviral therapy ${ }^{6}$-but with an evidence-based, feasible target with a fixed price tag, funders were willing to commit regardless.

Now, as low-income and middle-income countries (LMICs) continue rapid development, in some cases achieving outcomes far beyond the 2015 Millennium Development Goals, ${ }^{12}$ a new epidemic is rapidly becoming the next global health emergency. The rise of cardiovascular and other non-communicable diseases (NCDs) 
has become so acute that the UN in 2011 called its only health-related high-level meeting-save for prior HIV/ AIDS summits-to discuss solutions. ${ }^{13}$ Since then, hypertension, the leading cardiovascular risk factor, has become the leading cause of premature death and disability worldwide. ${ }^{14}$ To stem this tide requires similar decisive action, which in turn requires hard numbers on the size of the treatment gap and its price tag, especially as the role of bilateral global health financing is at a crossroads. ${ }^{3415}$

Unfortunately, programmes to fight NCDs like hypertension are markedly underfunded relative to their share of the global disease burden. From 2001 to 2008, less than $3 \%$ of all development assistance for health was dedicated to NCDs, ${ }^{16}$ although NCDs cause $60 \%$ of all disability-adjusted life years lost and $71 \%$ of all deaths worldwide. ${ }^{17}$ The reasons are debatable; a 2010 working paper cites 'the perceptions that NCDs predominate only in rich countries, that they are consequences of personal choices or an inevitable result of aging, and that they and cannot be cost-effectively controlled' ${ }^{16}$

The good news: we now have substantive evidence to debunk all three claims. Not only is hypertension more common and more severe in LMICs than rich ones, ${ }^{14}$ it can now be controlled far more cost-effectively in LMICs than HIV/AIDS. Antihypertensive medicines, called thiazides, can close the treatment gap for less than $\$ 20$ per person per year. Over a decade, they could save almost 5 million lives worldwide, at a cost under $\$ 9$ billion per year: significantly less than the estimates that galvanised the global HIV community 15 years ago.

Thiazides are the initial medication of choice for blood pressure control in nearly all settings. Although developed in 1958, they remain a drug of first resort according to the International Society for Hypertension (ISH), European Society for Cardiology and others. ${ }^{18-20}$ They are also generic, costing a dollar or less per year in developing countries. ${ }^{21}$ Although they require annual blood tests and doctor visits to screen for (rare) changes in kidney function, groups such as Partners in Health have treated patients with hydrochlorothiazide for \$4-13 per year in settings like Rwanda. ${ }^{21}$

As in the early days of HIV control, conventional wisdom holds that universal hypertension treatment is prohibitively expensive. In 2007, the WHO and ISH published guidelines arguing that only high-risk persons should receive antihypertensive medications, because 'treatment of [hypertensive] patients with very low CVD risk may be cost-effective only if inexpensive antihypertensive drugs are used'. ${ }^{18}$ Subsequent studies concurred, ${ }^{22}{ }^{23}$ in one case finding many patients spent $10 \%$ or more of their annual income on antihypertensive medications. ${ }^{23}$

Yet recent data suggest universal treatment is now cost-effective and a better value than HIV/AIDS treatment at the dawn of the Global Fund and PEPFAR. Partners in Health pays $\$ 0.3$ cents per thiazide tablet in Rwanda or $\$ 1.03$ per patient-year of treatment. ${ }^{21}$ Patients requiring further treatment receive amlodipine, whose annual cost is \$4.69. Each patient also receives one to two clinic visits per year at $\$ 3$ each, as well as laboratory tests costing $\$ 0.17$ per check. Conservatively, assuming that all patients require two medications, clinic visits and laboratory tests per year, these results correspond to a per-patient annual cost of $\$ 12.90$. Mills et $\mathrm{al}^{14}$ report that about $32 \%$ of all adults in LMICs have hypertension-approximately 1.039 billion people. Some $11.6 \%$ have chronic kidney disease, according to a recent systematic analysis ${ }^{24}$ or other severe hypertension $(9.1 \%$ in Partners in Health's cohort) requiring treatment beyond thiazides and amlodipine. ${ }^{21}$ Of the remaining 830 million, $29 \%$ are currently treated, ${ }^{14}$ leaving 589 million persons in need of treatment worldwide.

Treating all of these 589 million people, within Partners in Health's model, would cost $\$ 7.6$ billion per annumless than the $\$ 9$ billion estimated to close the AIDS gap in 2001, even before adjustment for inflation. ${ }^{6}$ Meta-analyses suggest that treatment of uncomplicated stage 1 hypertension saves one life per 72-125 persons treated over 5 years. ${ }^{25-27}$ Conservatively, assuming a number needed to treat of 125 , doubled to 250 on the presumption of a $50 \%$ adherence rate, ${ }^{28}$ closing the thiazide gap would save more than 4.7 million lives by 2027 , at a cost of $\$ 16125$ per life saved. By comparison, estimates of the cost-effectiveness of ART for HIV in 2001 ranged from $\$ 13000$ to $\$ 23000$ for each disability-adjusted year of life saved,$^{29}$ a trial-based calculation not necessarily incorporating adherence rates of $55 \%-77 \% .^{30}$

By focusing on the largest contributor to human mortality worldwide, we have the capacity to save a half-million lives per year-at a fraction of the price tag that galvanised political and institutional commitment against AIDS. We can make this choice or allow a disease to continue unchecked that now causes $13 \%$ of all human deaths worldwide, and incur some $\$ 908$ billion in health costs over the coming decade or more than $\$ 3.6$ trillion once the costs of lost life and work are included. ${ }^{31}$

Still not sold on the $\$ 7.6$ billion price of entry? We could instead treat only high-risk individuals as the WHO and ISH suggest: one meta-analysis reports the efficacy of treatment is 2.7 times greater in persons at $27 \%$-year risk than those with $6 \%$ risk. However, this approach would have less impact, because it treats far fewer people. The total fraction of adults at $30 \%+$ cardiovascular risk is between $0.2 \%$ and $4.8 \%$ according to empiric samples, ${ }^{32} 33$ some $10 \%-20 \%$ of those with hypertension. This approach may therefore cost only $\$ 1$ billion per year but would save, at most, a third as many lives as treatment for all.

How do we set this plan into motion? New operational research provides the tools for laypeople to test for and treat hypertension and other causes of heart disease such as smoking and obesity. ${ }^{34} 35$ Armed with these toolkits, we can replicate Partners in Health's Rwanda model even in sites without doctors, making the cost estimates above feasible in contexts previously thought impossible. A recent hypertension treatment trial in Nigeria, for example, projected a cost per disability-adjusted life year saved of $\$ 732-\$ 7815$ across scenarios, assuming a treatment cost of $\$ 112$ per patient per year. ${ }^{36}$ Yet the study that yielded this cost estimate noted 
that shifting tasks from doctors to nurses and decreasing appointment frequency could cut costs by up to $42 \%,{ }^{37}$ and Partners in Health has already reduced it by nearly $90 \%$. Thanks to these task-shifting models, the challenge is no longer the programme cost but the political climate.

The HIV/AIDS movement provides a solution here too: the summits of the early 2000s brought private and public stakeholders together to devise interventions and to secure their financing. In 2001, when the Bill and Melinda Gates foundation pledged $\$ 100$ million to the nascent Global Fund, it insisted that 'governments, the private sector and the nonprofit community all have to redouble efforts so that together we can break this chain of transmission', forming a new coalition of public and private partners. ${ }^{38}$ The UN has since hosted two high-level meetings on NCDs like hypertension, with a third looming in $2018 .{ }^{39}$ Meanwhile, foreign direct investment in Africa is five times greater than in $2000^{40}$; recognising this trend, more than 20 biopharmaceutical companies have partnered with the World Bank and the Union for International Cancer Control to address medication access gaps for NCDs in LMICs through the Access Accelerated initiative, among others. ${ }^{41}$ Providing care to the global workforce, in collaboration with these public, private and joint initiatives, generates healthier and more prosperous trading partners for wealthy nations and promotes global security more cheaply than military intervention. Even donor countries that place their own citizens' needs first now have a stake in this task-and a roadmap to get there. Will they seize the opportunity?

Twitter DJH's Twitter handle is @djheller. SPK's Twitter handle is @sandeep_ kishore.

Contributors DJH and SPK co-conceived the idea of the manuscript. DJH drafted, wrote, and edited the content of the manuscript. SPK provided input on the content, framing, writing and editing of the manuscript.

Funding DJH receives funding from the US National Institutes of Health's Fogarty International Center (grant number R21TW010452).

Competing interests None declared.

Provenance and peer review Not commissioned; externally peer reviewed.

Data sharing statement No other data are available.

Open Access This is an Open Access article distributed in accordance with the Creative Commons Attribution Non Commercial (CC BY-NC 4.0) license, which permits others to distribute, remix, adapt, build upon this work non-commercially, and license their derivative works on different terms, provided the original work is properly cited and the use is non-commercial. See: http://creativecommons.org/ licenses/by-nc/4.0/

(c) Article author(s) (or their employer(s) unless otherwise stated in the text of the article) 2017. All rights reserved. No commercial use is permitted unless otherwise expressly granted.

\section{REFERENCES}

1. Joint United Nations Programme on HIV/AIDS (UNAIDS), Joint United Nations Programme on HIV/AIDS (UNAIDS). Global AIDS update 2016. Geneva, Switzerland, 2016.

2. Sachs J. The end of AIDS. Project Syndicate, November 29, 2016. https://www.project-syndicate.org/commentary/end-of-aidsepidemic-by-jeffrey-d-sachs-2016-11(accessed 28 Jul 2017).

3. McNeil DG The New York Times. Trump administration puts the US at a crossroad for Global Health Aid. https://www.nytimes.com/ 2016/12/19/health/donald-trump-foreign-aid-global-health.html?_ $r=0$ (accessed 28 Jul 2017).

4. America First: a budget blueprint to make America great again, 2017. https://www.whitehouse.gov/sites/whitehouse.gov/files/omb/ budget/fy2018/2018_blueprint.pdf (accessed 28 Jul 2017).

5. UN security council resolution 1308 (2000) on the responsibility of the security council in the maintenance of international peace and security: HIV/AIDS and international peace-keeping operations. http://www.unaids.org/sites/default/files/sub_landing/files/ 20000717_un_scresolution_1308_en.pdf

6. Schwartländer B, Stover J, Walker N, et al. AIDS. Resource needs for HIV/AIDS. Science 2001;292:2434-6.

7. Commission on Macroeconomics and Health. $2001 \mathrm{http} / / / w w w . w h o$. int/macrohealth/background/who_hq_20Dec2001.pdf

8. The global fund to fight AIDS, tuberculosis, and malaria. Wikipedia. https://en.wikipedia.org/wiki/The_Global_Fund_to_Fight_AIDS, Tuberculosis_and_Malaria

9. World Health Organization. The world health report 2003: shaping the future: World Health Organization, 2003.

10. United States leadership against HIV/AIDS, tuberculosis, and malaria act of 2003. Public Law 108-25: 108th Congress https://www. congress.gov/108/plaws/publ25/PLAW-108publ25.pdf

11. Global fund praises new funding pledges by $\mathrm{G} 8$, underscores need for US $\$ 8$ billion by end of 2004. The global fund to fight AIDS, tuberculosis, and malaria. https://www.theglobalfund.org/en/news/ 2003-06-06-global-fund-praises-new-funding-pledges-by-g8underscores-need-for-usd-3-billion-by-end-of-2004/

12. Millennium development goals: 2015 progress chart. http://www. un.org/millenniumgoals/2015_MDG_Report/pdf/MDG\%202015\% 20PC\%20final.pdf

13. United Nations high level meeting on prevention and control of non-communicable diseases. 2011 http://www.un.org/en/ga/ ncdmeeting2011

14. Mills KT, Bundy JD, Kelly TN, et al. Global disparities of hypertension prevalence and controlclinical perspective. Circulation 2016;134:441-50.

15. The Telegraph. Conservative manifesto: tories to redraw definition of foreign aid to appease critical party members. $2017 \mathrm{http}: / / \mathrm{www}$. telegraph.co.uk/news/2017/05/18/conservative-manifesto-toriesredraw-definition-foreign-aid/

16. Nugent R, Feigl A. Where have all the donors gone? Scarce donor funding for non-communicable diseases. Center for global development working paper no. 228. https://ssrn.com/abstract= 1824392

17. Institute for Health Metrics and Evaluation. GBD compare viz hub. https://vizhub.healthdata.org/gbd-compare/

18. World Health Organization. Prevention of cardiovascular disease: guidelines for assessment and management of cardiovascular risk: World Health Organization, 2007.

19. Mancia G, Fagard R, Narkiewicz K, et al. ESH/ESC guidelines for the management of arterial hypertension: the Task Force for the Management of Arterial Hypertension of the European Society of Hypertension (ESH) and of the European Society of Cardiology (ESC). Blood pressure 2013;22:193-278.

20. James PA, Oparil S, Carter BL, et al. Evidence-based guideline for the management of high blood pressure in adults: report from the panel members appointed to the Eighth Joint National Committee (JNC 8). JAMA 2014;311:507-20.

21. Bukhman G, Kidder A. The PIH guide to chronic care integration for endemic non-communicable diseases: Partners in Health, 2011.

22. Gaziano TA. Economic burden and the cost-effectiveness of treatment of cardiovascular diseases in Africa. Heart 2008;94:140-4.

23. Ilesanmi OS, Ige OK, Adebiyi AO. The managed hypertensive: the costs of blood pressure control in a Nigerian town. Pan Afr Med $\mathrm{J}$ 2012;12.

24. Mills KT, Xu Y, Zhang W, et al. A systematic analysis of worldwide population-based data on the global burden of chronic kidney disease in 2010. Kidney Int 2015;88:950-7.

25. Sundström J, Arima H, Jackson R, et al. Effects of blood pressure reduction in mild hypertension: a systematic review and metaanalysis. Ann Intern Med 2015;162:184-91.

26. Sundström J, Arima $\mathrm{H}$, Woodward $\mathrm{M}$, et al. Blood pressure-lowering treatment based on cardiovascular risk: a meta-analysis of individual patient data. Lancet 2014;384:591-8.

27. TheNNT.com. Anti-hypertensives to prevent death, heart attacks, and strokes. http://www.thennt.com/nnt/anti-hypertensives-toprevent-death-heart-attacks-and-strokes/.

28. Peacock E, Krousel-Wood M. Adherence to antihypertensive therapy. Med Clin North Am 2017;101:229-45. 
29. Freedberg KA, Losina E, Weinstein MC, et al. The cost effectiveness of combination antiretroviral therapy for HIV disease. N Engl J Med 2001;344:824-31.

30. Mills EJ, Nachega JB, Buchan I, et al. Adherence to antiretroviral therapy in Sub-Saharan Africa and North America: a meta-analysis. JAMA 2006;296:679-90.

31. Gaziano TA, Bitton A, Anand S, et al. The global cost of nonoptimal blood pressure. J Hypertens 2009;27:1472-7.

32. Otgontuya D, Oum S, Buckley BS, et al. Assessment of total cardiovascular risk using WHO/ISH risk prediction charts in three low and middle income countries in Asia. BMC Public Health 2013;13:539.

33. Mendis S, Lindholm LH, Anderson SG, et al. Total cardiovascular risk approach to improve efficiency of cardiovascular prevention in resource constrain settings. J Clin Epidemiol 2011;64:1451-62.

34. Mendis S, Johnston SC, Fan W, et al. Cardiovascular risk management and its impact on hypertension control in primary care in low-resource settings: a cluster-randomized trial. Bull World Health Organ 2010;88:412-9.

35. Hearts: technical package for cardiovascular disease management in primary health care: World Health Organization, 2016.
36. Rosendaal NT, Hendriks ME, Verhagen MD, et al. Costs and CostEffectiveness of Hypertension Screening and Treatment in Adults with Hypertension in Rural Nigeria in the Context of a Health Insurance Program. PLoS One 2016;11:e0157925.

37. Hendriks ME, Bolarinwa OA, Nelissen HE, et al. Costs of cardiovascular disease prevention care and scenarios for cost saving: a micro-costing study from rural Nigeria. $J$ Hypertens 2015;33:376-684.

38. Bill and melinda gates foundation announces $\$ 100$ million commitment to the global fund for aids and health. http://www. gatesfoundation.org/Media-Center/Press-Releases/2001/06/GlobalFund-For-AIDS.

39. Getting to 2018: preparing for the third UN high-level meeting on NCDS. http://www.who.int/nmh/events/2015/gettingto-2018/en/.

40. Diop M, Li Y, Yong L, et al. Africa still poised to become the next great investment destination. http://www.worldbank.org/en/news/ opinion/2015/06/30/africa-still-poised-to-become-the-next-greatinvestment-destination.

41. Access accelerated: moving NCD care forward. http://www. accessaccelerated.org/about/. 